\title{
PALEOENVIRONMENTAL STUDY OF OUM ALI REGION (TÉBESSA, ALGERIA) DURING QUATERNARY, THROUGH THE STUDY OF FLUVIAL TERRACE OF KHENIGUE WADI
}

DOI: https://doi.org/10.18509/AGB217-40153n

UDC: 551.435.7.07:528.526.1(65)

\section{Defaflia Nabil $^{1}$, Djaiz Fouad ${ }^{2}$, Fehdi Chamseddine ${ }^{3}$}

\begin{abstract}
${ }^{1}$ Université Larbi Tbéssi de Tébessa, Faculté des Sciences Exactes et des Sciences de la Nature et de la Vie. ${ }^{2}$ Université Mostefa Ben Boulaid Batna 2, Institut des Sciences de la Terre et de l'Univers, Dépt. De Géologie. ${ }^{3}$ Université Larbi Tbéssi de Tébessa, Faculté des Sciences Exactes et des Sciences de la Nature et de la Vie.
\end{abstract} corresponding author: defaflianabil@yahoo.fr

\begin{abstract}
Stratigraphic, sedimentological and magnetic study was performed on alluvial terraces, rich in archaeological tools, the region of OUM ALI, in north-eastern Algeria. The sedimentological points of view, the sediments are dominated by the sand fraction followed by the silt fraction; moderate concentrations of $\mathrm{CaCO} 3$ are the result of the dissolution of the surrounding limestone reliefs (Maastrichtian limestone). The morphoscopic observation of quartz grains with a dissecting microscope allows us to offer more or less significant changes, since they are often dull or sub-blunted.

The results of the magnetic survey are consistent with those of the sedimentological study. The values of magnetic susceptibility are strong in the middle part of the stratigraphic section (just above the archaeological level) and decrease slightly at the top. Lower values are stored in the lower part. The dependence of frequency values of magnetic susceptibility ( $\square \mathrm{fd}$ ) are strong throughout the stratigraphic section and show the presence of a mixture of single-domain grain size (R), pseudo-single domain (PMD) and superparamagnetic (SP) (with a predominance of SP grains). The high concentration of SP grain size reveals the presence of significant soil formation during the implementation of the sediment.
\end{abstract}

Keywords: Oum Ali, fluvial terraces, Quaternary, Magnetic susceptibility, Late Pleistocene, Holocene.

\section{INTRODUCTION}

The site of Oum Ali is located to the south of the city of Tébessa, located at 250 kilometers from the Mediterranean Sea. It is bordered to the north by a chain of mountains of medium to high altitudes (Jebels Doukkane, Anoual and Bouroumane) (Fig.1). The present work is to study stratigraphic, sedimentological and magnetic (magnetic susceptibility) of Quaternary sedimentary formations of alluvial terraces at Oum Ali area in order to better characterize paleoenvironmental characteristics, especially the climate in the prehistoric period from the Aterian during Neolithic. The area of Oum Ali, is located on the edge of the Algerian-Tunisian border and is part of the Saharan Atlas. The reliefs are mixed, consisting essentially of Maastrichtian limestone along a SWNE axis, and separated by a Mio-Quaternary depression (cultivated plain of El Ma El Abiod).

This structure is due to two tectonic phases that have affected the region (Atlas phase -between the upper- Miocene and lower Lutetian, and dated phase of Miocene). The macroscopic field observation allowed the subdivision of the geological section in seven different stratigraphic levels, indexed from 1 to 7 (Fig. 2).

Level 1: is localized between $0-50 \mathrm{~cm}$ (thickness $=$ $50 \mathrm{~cm}$ ).It is formed mainly of gravel and pebbles $(60 \%)$ and roller $(10 \%)$ of white limestone with an irregular shape and jagged edges. The degree of damage is low. The matrix (30\%) is thin and with olive color. The carbonates rate is 39.62 to $46.29 \%$, and the sediment is rich in organic matter (abundance of rosemary roots / absence of human activity traces / abundance of snails debris (= traces animal activity)).

Level 2: localizes between -50 and $-65 \mathrm{~cm}$ (thickness $=15 \mathrm{~cm}$ ).It consists mainly of fine matrix ( $70 \%$ of total), brown olive color (dark), and rich in organic matter. The carbonate content is from 42 to $47 \%$. We notice a few spots, the absence of of human activity evidence and abundance of debris shells (traces of animal activity). Gravel and pebbles $(30 \%)$, whitish calcareous nature have an irregular shape and angular edges, the degree of 
damage is low. The predominance of the fine fraction (clay and silt) indicates a dry climate and low water flow.

Level 3: localizes between -65 to $-90 \mathrm{~cm}$ (thickness $=25 \mathrm{~cm}$ ).It is mainly composed of gravel and pebbles $(60 \%)$ of calcareous nature and whitish, with irregular shape and angular edges, the degree of damage is low.The matrix $(40 \%)$ is thin and olive-colored (clear), it contains $46-47 \%$ of carbonates and is rich in organic matter (plant roots). There is a lack of spot and traces of human activity, and abundance of snail debris (traces of animal activity).

Level 4: locates between - 90 and $-107,5 \mathrm{~cm}$ (thickness $=15 \mathrm{~cm}$ ).It is formed essentially of fine matrix (80\%), brown olive color (dark), and containing little organic matter (traces of roots). The carbonate content is from 51 to $52 \%$. We see the presence of some spot, no trace of human activity and abundance of snail debris (traces of animal activity). Gravel and pebbles (20\%) are whitish calcareous nature with an irregular shape and angular edges.

Level 5: locates between 107.5 and $-123,5 \mathrm{~cm}$ (thickness $=17 \mathrm{~cm}$ ). It is mainly composed of gravel

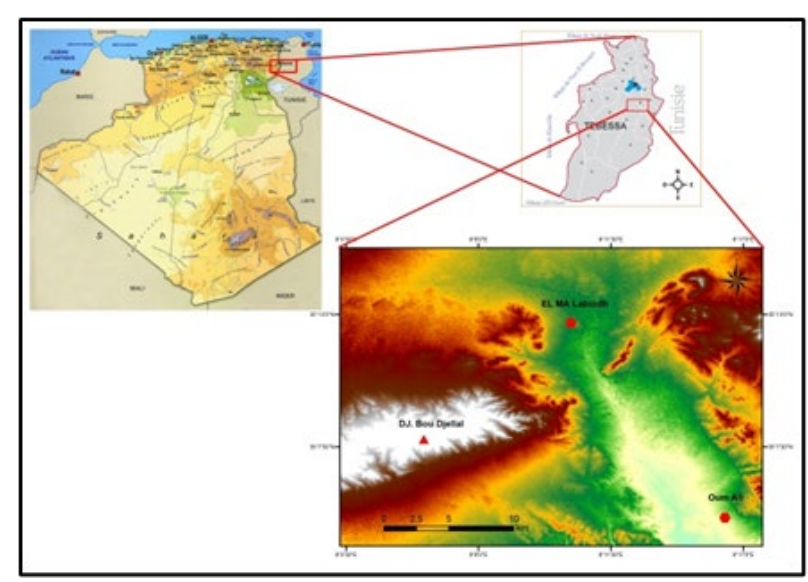

Figure 1: Geographical situation of Oum Ali site Tébessa, Algeria

\section{METHODOLOGY AND MATERIAL}

In the laboratory, two types of analyzes were undertaken:

\subsection{The sedimentological analysis}

They include the size analyzes, dosage of carbonates and morphoscopic study of quartz grains and clay mineralogy. Prior to analysis, the raw sample, sieved to $2 \mathrm{~mm}$, was dried in an oven at a temperature of $40^{\circ} \mathrm{C}$. The garnulometry of fine particles was conducted on [1] granulometer with laser diffraction. The sources are a red He-Ne Laser at $632 \mathrm{~nm}$ for the detection of large particles and a and pebbles (65\%), of calcareous nature and whitish, with irregular shape and angular edges. The matrix is fine $(35 \%)$, olive color (clear) and contains 46 to $47 \%$ of carbonates. It is rich in organic matter (plant roots). There is a lack of spot and traces of human activity, and abundance of snail debris (traces of animal activity).

Level 6: localizes between -123.5 and $-147 \mathrm{~cm}$ (thickness $=23 \mathrm{~cm}$ ). It consists mainly of fine matrix ( $80 \%)$, brown olive color (dark), containing some of organic matter (roots). The carbonate content is between 45 and $57 \%$. We see the presence of some spot, no trace of human activity and abundance of snail debris (traces of animal activity) .The gravel and pebbles (20\%), whitish calcareous nature have an irregular shape and angular edges.

Level 7: is localized between -147 and $-176 \mathrm{~cm}$ (thickness $=29 \mathrm{~cm}$ ). It is mainly composed of gravel and pebbles $(60 \%)$, of calcareous nature and whitish, with irregular shape and angular edges. The matrix $(40 \%)$ is thin, olive-colored (clear) and contains 37 to $47 \%$ of carbonates. There is a lack of spot and traces of human activity, and abundance of snail debris (traces of animal activity).

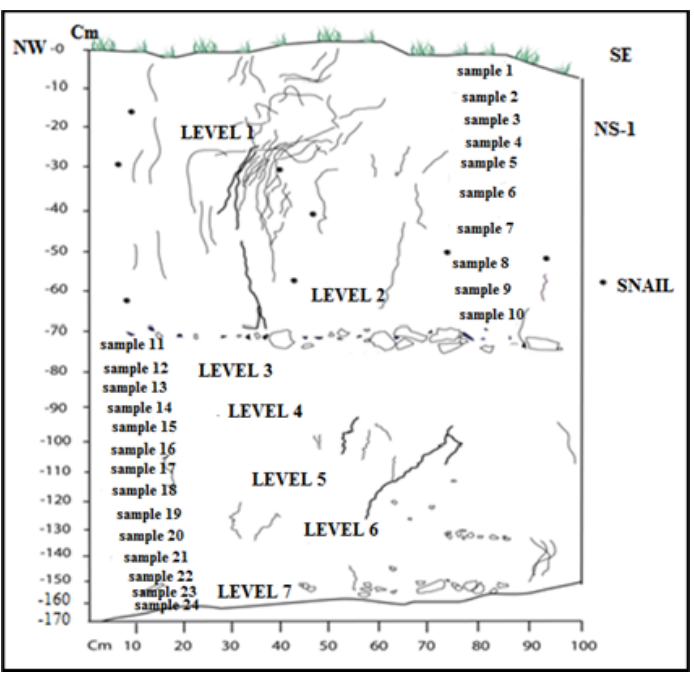

Figure 2: Stratigraphical $\log$ of the studied terrace.

blue LED at $466 \mathrm{~nm}$ for the detection of fine particles. Each sample was analyzed simultaneously wet and dry first on crude fraction and then the same fraction decalcified. For the calculation of parameters and indices of sand, we used the manual granulometer [1] (Mastersizer $\square 2000$ ) and interpretation of the results to the works of [2], [3], [4], [5] and [6]. The various indices are selected those most used during the past decade.

Average: average is called a logarithmic or arithmetic average distribution (according to the 
nature of the abscissa) values of the independent variable. This parameter provides information on the average size of the sample and hence the energy of the environment and transport distance. It is defined by the following formula: $\mathrm{Mz}=(\mathrm{Q} 16+\mathrm{Q} 50$ + Q84) / 3, Mz size and Folk Ward Average

Skewness, Sk : This skewness characterizes the degree of distortion of the symmetry of the distribution. When the skewness is zero, this means that the asymmetry is perfect (median, mode and mean coincide). When it has negative values, it is the fine grains that are highly ranked; positive values correspond to good ranking coarse grains. This parameter reflects better the depositional environment as the conditions of transport.

The Kurtosis: is representative of the sharpness of the peak (width) when it is zero, the curve is called mesokurtic or moderately sized, when it is greater than 0 , the curve is called leptokurtic, this means that the distribution is classified, which is a modal marker at constant power. If the kurtosis is negative, it means that the distribution is misclassified (platykurtic).The morphoscopic study, develop [7] is applied to the quartz grains, decarbonatation in cold conditions of the fraction between 0.5 and $0.25 \mathrm{~mm}$. It is performed using a binocular microscope and it consists to examine the shape and appearance of quartz grains in order to provide information on the transport mode of these grains. The calcimetry was measured systematically. Its consist of the determination of the calcium carbonate percentage on $0.5 \mathrm{~g}$ of ground and dried sediment of less than $2 \mathrm{~mm}$ size, using the Bernard calcimeter.

Concerning clay mineralogy, we used the method developed [8]. The analyzes were performed by Xray diffraction on oriented aggregates. The study of clay mineralogy was performed by a diffractometer equipped with a copper anticathode. The settings are optimized to work in small angles $\left(30^{\circ}\right)$ which

\section{RESULTS AND INTERPRETATION}

\section{1. sedimentological study}

The sedimentological study was performed on 26 samples taken systematically from the top to the base of the stratigraphic section.

The study of the gross particle size fraction smaller than $2 \mathrm{~mm}$ (Fig. 3) allowed to individualize seven stratigraphic levels, some rich coarse fraction (gravel and pebbles) alternating with high levels of silt. The percentage of the clay fraction is very low and remains almost constant almost throughout the stratigraphic section. The particle size of the fine diffract mainly clay minerals. For the determination of clay minerals, the following works were consulted: [9], [10], [11], [12], and [13].

\subsection{Magnetic analyzes}

Magnetic methods allow a- to reveal variations, particularly in the filings, which are not necessarily obvious to the naked eye,

b- to classify different types of materials, c- to identify and transport processes formation of magnetic grains,

d- to propose a paleoclimatic interpretation [14] ; [15]. All magnetic measurements were made on samples of the unoriented, dried and consolidated with an aqueous solution of sodium silicate, in order to prevent movement of the grains during handling. The following magnetic properties were measured:

1-the mass magnetic susceptibility $(\chi)$ : with low frequency $(0.46 \mathrm{kHz})$ and high frequency $(4.65$ $\mathrm{kHz}$ ) was measured with a Bartington susceptibilimetre MS2B MS2 connected to a probe, 2-frequency of the magnetic susceptibility dependence ( $\square \mathrm{fd}$ ): Is calculated from the previous parameter using the formula:. $\left.\chi_{\mathrm{fd}}=\left(\left(\chi_{\mathrm{bf}}-\chi_{\mathrm{hf}}\right) / \chi_{\mathrm{bf}}\right)\right) \mathrm{x}$ $100 \%$ (Maher et al 1986; Maher 1988; Mullins 1977). This parameter specifically detect the presence of small magnetic grains ( $\square 0.03$ microns) showing a superparamagnetic behavior.

3-The procedure proposed by Lowrie (1990) was also applied to some samples. This procedure is based on the analysis of the thermal demagnetization three ARI induced in the laboratory according to three orthogonal axes. We chose a field of $2.5 \mathrm{~T}$ along the axis $\mathrm{Z}$, of $300 \mathrm{MT}$ along the $\mathrm{X}$ axis and $20 \mathrm{mT}$ along the axis $\mathrm{Y}$. This procedure allows highlighting the existence of several populations of magnetic grains which differ in their chemistry or size [16] [17].

fraction (Fig. 3) shows a relatively uniform sediment, with very little clay $(0.69 \%$ on average), a high silt rate $(77 \%)$ and fine sand percentages and coarse moderate (10 and 15\% respectively). They are aware of a development parallel to that of gravel and pebbles. Level 1 , in which the silty fraction increases at the expense of the coarse fraction (coarse and fine sand), is an exception. Within 4 and 5 levels, the proportion of coarse sands increases to the detriment of silt. 


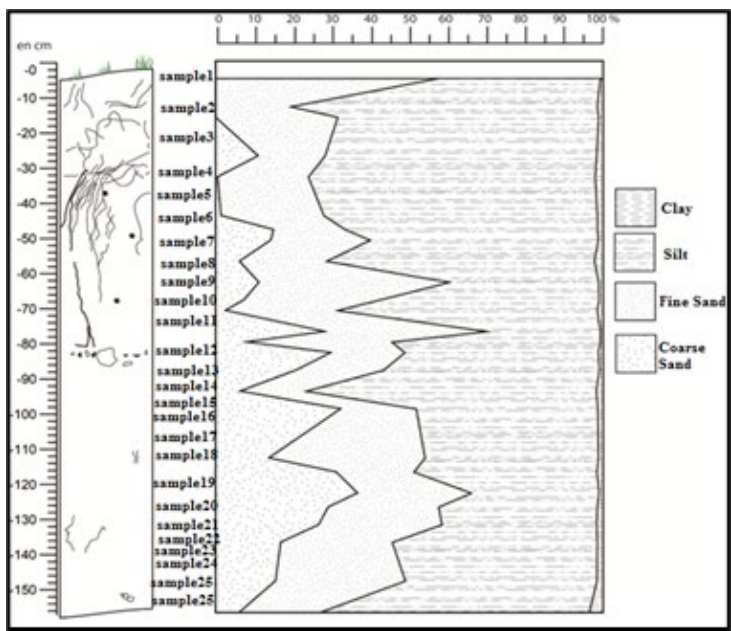

Figure 3: Fine sediments granulometry

\subsection{Grain size characteristics}

The cumulative size distribution curves of gross sand fractions have variable shape. Some cumulative curves are upturned and said facies "parabolic" (Fig. 4). This applies to samples 1 and 2 the upper part of the terrace and corresponds to immature sediments that have not evolved over time and has undergone a redesign transport [6].

The cumulative curves downward facing (hyperbolic facies) (fig. 4) are also present and

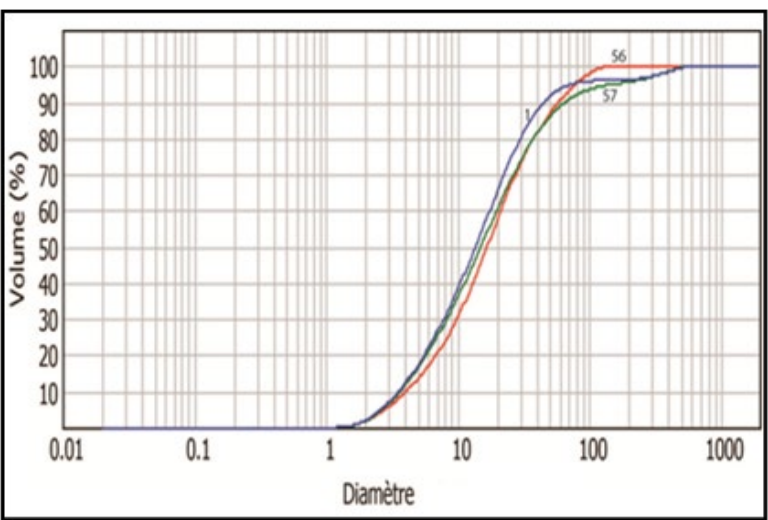

Figure 5: Cumulative curve of specimens 3,56 and 57

After calcining, the curves of the majority of samples did not change their paces and appoint a misfiled sand, except the sample No. 1, which shows a hyperbolic curve (although classified sand) (fig. 6) The median and the other granulometric parameters of this sample decreased, which is due to the enrichment of the carbonate-containing material in material. The average values vary between 10 and 32 (Fig. 7) and relatively low to moderate $(<50$ microns) in all layers. These low values are due to the preponderance of silty sand fraction. The deposition of the fine fraction is relatively well in relation to a rise in water level. Kurtosis of the values range between 0.7 and 1.60 (fig. 7), frequency histograms are type platykurtic

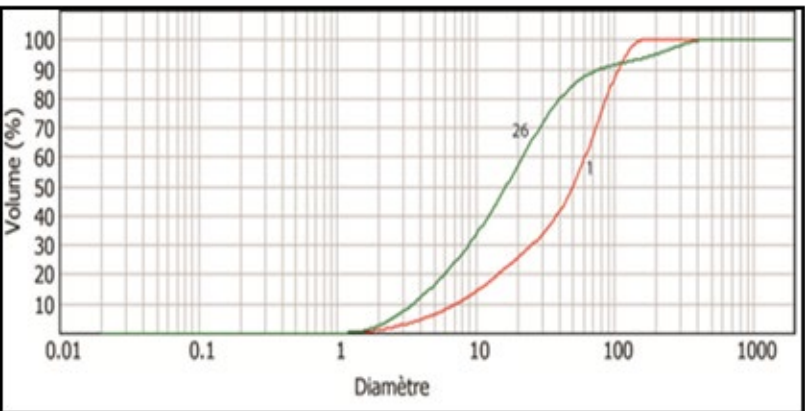

Figure 4: Cumulative curve of specimens 1 and 26

demonstrate a calm environment, sedimentation settling. This type of sedimentation concerns especially the samples 26 and 40 of the middle and lower part of the terrace Some samples show cumulative curves for sub-logarithmic $\log (3,50$ and 51, 53, 57, 59, 60, 63, 64 and 67 (Fig. 5). This is sediment silty dominance which characterizes a medium calm, which are deposited by excess load upon reduction of the speed of transport..

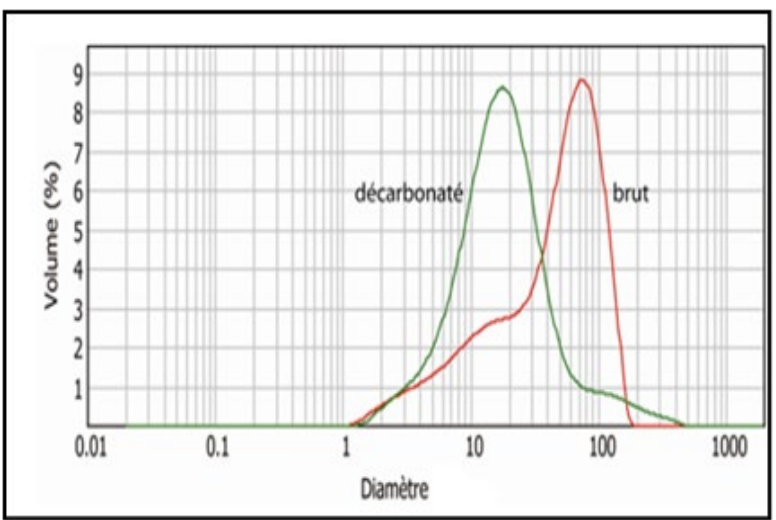

Figure 6: Frequency curve specimen $\mathrm{N}^{\circ} 1$ (brut and decarbonated).

to mesokurtic sometimes leptokurtic. This evolution and shows the presence of a low ranking sediment levels and others to average to good ranking. Indeed, when Coulter indicated that a curve is platykurtic, it happens that certain methods of fine sands are indicated as leptokurtic but because platykurtics associated with silts and clays very misclassified.

The skewness values are negative or close to zero (Fig. 7), they show that the spread of the histogram is the side of the fine fraction. In other words, the ranking is better on the side of coarse elements that the side ends. The ternary diagram shows that sediments consist mainly of silt and sand with silt dominant in the upper part (Fig. 8). 


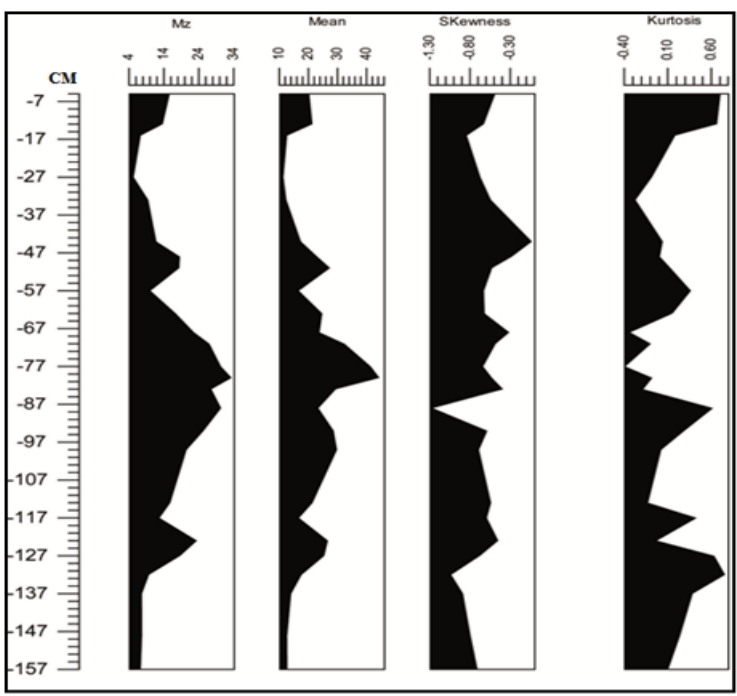

Figure 7: Result s of different size index

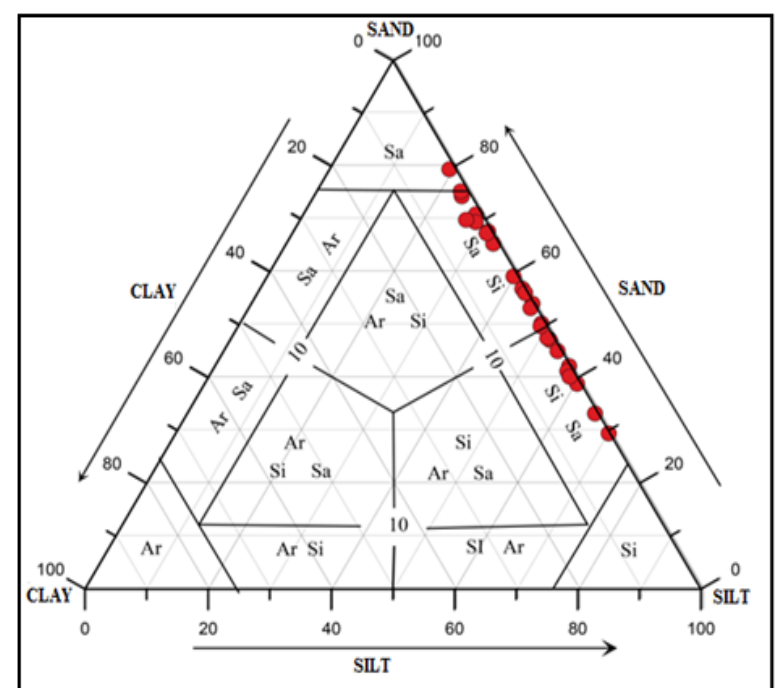

Figure 8: Ternary diagram of the granulometric denomination of the fine sediment

quartz grains could have originated Miocene sand, very present in the region. The presence of a coating on some ferruginous grains indicates the beginning of a soil formation. The unworn (UN) have a low percentage $(17.65 \%)$. The presence of these grains reflects a source of near intake, with unsophisticated sediments.

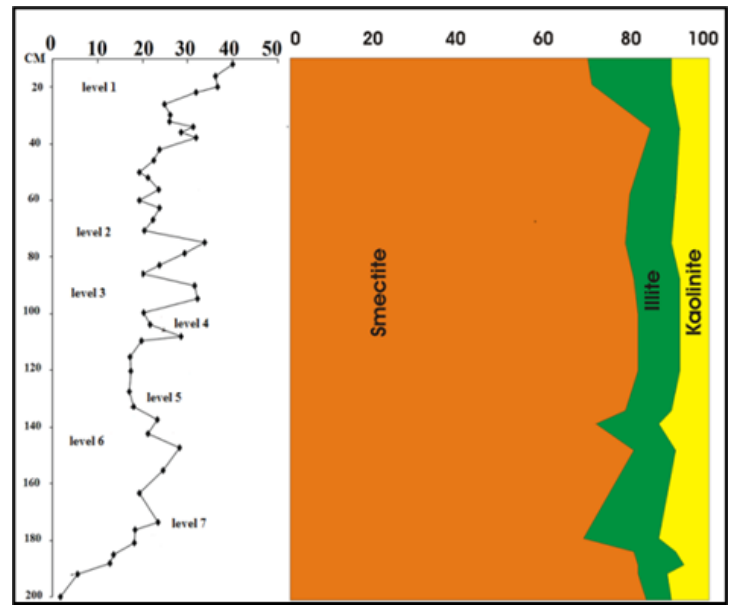

Figure 10: XRD Diffractograms of levels 1.2 to 7

well crystallized. Kaolinite, indicated by the natural peaks: $7.14^{\circ} \mathrm{A}(001)$ and $3.57 \mathrm{~A}^{\circ}(002)$ (fig. 10). It is $23.64 \%$ on average. The contents are not homogeneous throughout the cut. The highest levels $(24.58 \%)$ are recorded in the level $\mathrm{E}$ and the contents are low in level D $(18.75 \%)$. The crystallinity of this mineral is also perfect. Illite is shown by natural peaks: $7.14 \mathrm{~A}^{\circ}(001)$ and $3.57 \mathrm{~A}$ $\circ$ (002), and its disappearance after heating at $90 \%$. It represents ( $7.53 \%$ on average). The contents are homogeneous throughout the cut. This mineral does not have good crystallinity. The origin and clays forming conditions are diverse. Thus, illite is 
formed in cold climates and / or dried [9] [18] [19]. It comes from the weathering of silicate rocks.

Smectite is formed in large quantities under the action of a hot climate with alternating wet and dry phases [19]. Smectite is a fairly common mineral in

\subsection{Magnetic study}

The values of the magnetic susceptibility are strong in the middle part of the stratigraphic section just above the archaeological level (fig. 11) and decreased slightly at the top. Lower values are stored in the lower part. The dependence of frequency values of magnetic susceptibility ( $\square \mathrm{fd}$ ) are strong throughout the stratigraphic section and show the presence of a grain size mixture MD, PMD and SP (with a predominance of SP grains). The high concentration of SP grain size reveals the presence of significant soil formation during the implementation of the sediment. Results for calcimetry are fairly homogeneous (Figure 11), with an average content of $32 \%$ carbonate (14 to $46 \%)$. However, their percentages are increasing at the same levels as the coarse fraction (gravel and stones) and coarse sand register moderate proportions. It is therefore possible to think that these three fractions have the same origin. We believe that some of these limestones are synsedimentary and could precipitate from the dissolution of the surrounding limestone reliefs

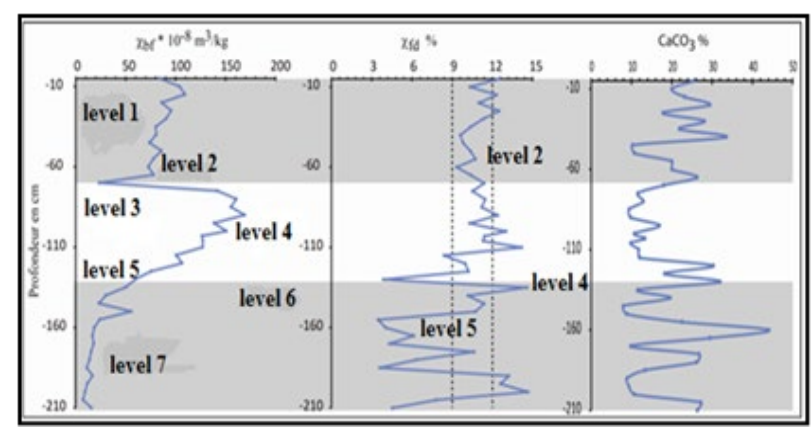

Figure 11: A; Magnetic susceptibility.

B; Frequency dependent magnetic susceptibility (\%). $\mathrm{C}$ : Percentage of $\mathrm{CaCO} 3$.

\section{CONCLUSION}

The parameters obtained from these results (particle size, rock magnetism, and clay mineralogy and crystal grain morphoscopy). Allow the subdivision of the terrace of Oum Ali in 7 stratigraphic levels. The particle size results indicated that the sediments have a weak (less than 50 microns), which is due to their enrichment in silt and fine sand. The frequency curves are platykurtic type mesokurtic sometimes leptokurtic. This development shows the low ranking of the analyzed sediments. Values $\mathrm{KG}$ (kurtosis) are negative or close to zero and show that spreading of the curve is on the side of the fine fraction. Sorting The index values show that sedimentary systems making its interpretation difficult. In the Mediterranean, it is mainly provided by the rivers and wadis. Kaolinite is the most abundant in hot and humid climate, runoff or drainage ensures the evacuation of ions.

(Maestrichtian limestone).

The test [16] allows studying the different coercivity families present in the fill. A sample $\left(\mathrm{n}^{\circ}\right.$ 12) has been subjected (Fig. 12). The principle of this test is the thermal demagnetization in zero fields, up to $700^{\circ} \mathrm{C}$, the sample according to three components of coercivity. The study of families in low coercivity is performed along the $\mathrm{X}$ axis, compared to medium coercivity along the $\mathrm{Y}$ axis and those of high coercivity along the axis $Z$. This test determines the Curie temperatures for different population's together time. These release temperatures are represented by slope changes corresponding to the magnetic remanence of losses of minerals. The presence of hematite $\left(680^{\circ} \mathrm{C}\right)$ and goethite (between 80 and $120^{\circ} \mathrm{C}$ ) (fig. 12) has allowed to estimate the average annual temperature and soil moisture at $17^{\circ} \mathrm{C}$ and 500 and $600 \mathrm{~mm}$ (hot and humid environment). This indicates that the climate was much wetter than at present $\left(15.6^{\circ}\right.$ $\mathrm{C}$ and $270 \mathrm{~mm}$ ) in the Tébessa region.

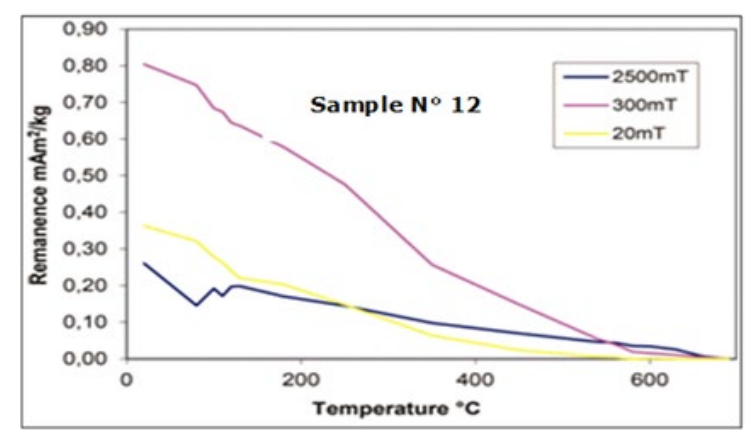

Figure 12: Lowrie diagram of specimen $\mathrm{N}^{\circ} 12$

classification is bad, very bad to very bad and therefore they relate irregularity of the energy level of the transport agent, and more particularly in the level 5 very rich in gravel.

Sediment of level 1,2,3 and 4 show a single stock (uni-modal frequency curves) represented by silts $(>75 \%)$, unlike those of the middle and lower part (levels 2 and 3) are bi to tri-modal, reflecting a mixture of two to three populations (sand and silt). The morphoscopic observation of quartz grains with a dissecting microscope allowed proposing more or less significant changes, since they are often dull or sub-blunted. The abundance of these 
quartz grains families induces a water transport (the importance of fluvial reworking). The magnetic survey is not going against these results. The magnetic parameters have high values in the middle and upper portion, and lower in the lower part. The decrease in the SM values in this part of the terrace is linked mainly to the dominance of gravel and sand (diamagnetic material) deposited under a strong hydrodynamic regime. The dependence of frequency values of magnetic susceptibility ( $\square \mathrm{fd}$ ) are strong throughout the stratigraphic section (except in the lower part) and indicate the presence of a grain size mixture MD, PMD and SP (with a predominance of SP grains). The high percentage of SP grains is linked to the bio-geochemical postdepositional sediment changes (important soil formation). The sedimentary deposit of this cut is implemented during the late Middle Pleistocene (NS-4), the Late Pleistocene (NS-7) and the end of the Pleistocene and the Holocene (NS-1) under conditions milder climate than the present. Variations on the curves of the overall size are the result of the alternation of a calm environment conducive soil formation, with a dynamic system characterized by the dominance of the coarse fraction (gravel and stone).

\section{REFERENCES}

[1] Mastersizer, Initiation au développement de méthode pour les poudres et les suspensions. (2000).

[2] P.L. Folk, W.C. Ward, Brazos river bar: a study in the significance of grain size parameters. Journal of Sedimentary Petrology, 27, (1957) pp. 3-26.France.

[3] A. Rivière, Méthodes granulométriques. Techniques et interprétations. Coll. Techniques et méthodes granulométriques. Masson édition, Paris, (1977). $170 \mathrm{p}$.

[4] K. Pye, S.J. Blott, Particle size analysis of sediments, soils and related particulate materials for forensic purposes using laser granulometry. Forensic Science International. (2004) 144, pp. 19-27.

[5] J.R. Anderson, Sand Sieve Analysis. In Pamela J. W. Gore "Historical Geology Online Laboratory Manual". Department of Geology. Georgia Perimeter College. (2007)278 p.

[6] J.C. Miskovsky. Géologie de la Préhistoire, méthodes, techniques, applications. Association pour l'étude de l'environnement géologique de la Préhistoire. Paris, Géopré, Presses universitaires de Perpignan. (2002),1519 p.

[7] A. Cailleux, J.Tricart, Initiation à l'étude des sables et des galets. Centre de documentation universitaire, Paris, (1963).369 p.

[8] T. Holtzapffel, Les minéraux argileux ; préparation, analyse diffractométrique et détermination. Société géologique du nord, (1985), 12, $136 \mathrm{p}$.

[9] G. Millot, Géologie des argiles. Masson, Paris, (1964). 499 p.

[10] G. Pedro, La classification des minéraux argileux (Phyllosilicates). Étude historique et considérations critiques. Institut National de la Recherche Agronomique. Annales Agronomiques. (1965). 16, 1, 108 p.

[11] M. Rober, Principes de détermination qualitative des minéraux argileux à l'aide de rayons X. Annales Agronomiques. (1975). 26, 4, pp. 363-399.

[12] S.Caillère, M. Henin, Rautureau, Minéralogie des argiles. 1. Structures et propriétés physico-chimiques. INRA, Actualités scientifiques et agronomiques, 8, Masson édition, 2e éd., Paris, (1982) .184 p.

[13] P. Larqué, Diffractométrie. Minéralogie de la fraction argileuse. In : Géologie de la Préhistoire, GEOPRE éditeur, (2002). pp. 601-613.

[14] A. Djerrab, T. Aïfa, Stratigraphy and Palaeoenvironment of the Karaïn Cave Infill, Antalya, Turkey. Rock Magnetic Investigations. Studia Geophysica et Geodaetica, (2010a), 54, pp. 49-76.

[15] A. Djerrab, I. Hedley IEtude des minéraux magnétiques du site préhistorique de la Caverna delle Fate (Finale Ligurie, Savona, Italie). Quaternaire, 21, 2, (2010b). pp. 265-280

[16] W. Lowrie, Identification of ferromagnetic minerals in a rock by coercivity and unblocking temperature properties. Geophys. Res. Lett.17, 2, (1990). pp. 159-162.

[17] W. Westphal et al., Magnetostratigraphy of the lower Triassic volcanics from deep drill SG6 in western Siberia: evidence for long-lasting Permo-Triassic volcanic activity. Geophys. J. Int. 134, (1998). pp. 254-266.

[18] H. Paquet, Evolution géochimique des minéraux argileux dans l'altération et les sols des climats méditerranéens et tropicaux à saisons contrastées. Thèse de Doctorat d'Etat, Université de Strasbourg, (1969). 348 p.

[19] H.Chamley, North Atlantic clay sedimentation and paleoenvironment since the late Jurassic. En: Deep Drilling Research Atlantic Ocean: Continental Margins and paléoenvironment (Talwani, M., Hay, W. and Ryan, W.B.F (Eds.). American Geophysical Union. Maurice Ewing Ser, 3, (1971).pp. 342-361 